\title{
The value of food safety culture to the hospitality industry
}

\author{
by Manning, L.
}

Copyright, Publisher and Additional Information: This is the author accepted manuscript. The final published version (version of record) is available online via Emerald Publishing.

This version is made available under the CC-BY-ND-NC licence:

https://creativecommons.org/licenses/by-nc-nd/4.0/

Please refer to any applicable terms of use of the publisher

DOI: $\underline{\text { https://doi.org/10.1108/WHATT-02-2018-0008 }}$ 


\title{
The value of food safety culture to the hospitality industry Louise Manning \\ Harper Adams University, Newport, Shropshire, TP10 8NB
}

\begin{abstract}
Purpose: This paper sought to review existing literature in the discipline of food hospitality with specific emphasis on the interaction between food safety management, food safety management systems (FSMS) and food safety culture.
\end{abstract}

Design/methodology/approach: This review examines academic literature on FSMS and food safety culture and emerging tools and methods being used to determine their efficacy. Findings: FSMS provide a framework for determining the resources required and the procedures and protocols, monitoring and verification necessary to deliver safe food. However, a performance gap has been identified in the literature between intended and actual food safety practice. The factors, rituals and behaviours that mediate this divide have been termed by many as "food safety culture". It has been shown that food safety knowledge does not necessarily lead to behaviour that promotes food safety. Thus the knowledge-experience-attitude-behaviour (KEAB) dynamic of food safety culture is of crucial importance and worthy of further empirical study in the hospitality industry.

Originality/value: The paper will be of value to practitioners, researchers and other stakeholders involved in the hospitality industry.

Key words: food safety management systems, food safety climate, food safety culture, food service, restaurants, hotel

Paper type: Review paper

\section{Introduction}

The hospitality industry is a broad sector including businesses as diverse as theme parks, event planning, cruise ships, hotels, restaurants and so forth. This means that the nature and style of the organisations varies widely as do the types of food and meal occasions and the knowledge and skill levels of those employed at all levels in the industry. This makes the embedding of food safety management systems (FSMS) difficult in this sector and no one approach fits all. There has been increasing interest not only in how food safety is managed within an organisation, but also how the culture of the organisation and the external business climate in which the business operates influence the effective implementation of those systems.

BSI EN ISO 9001: 2015 defines the term "quality" as the "degree to which a set of inherent characteristics (distinguishing features) fulfils requirements" whereas Crosby (Oakland, 1993) states quality is "conformance to customer requirements". Quality assurance (QA) can be described as the strategic management function involved with the establishment of policies, standards and systems for the maintenance of quality of products and services (Early, 1995). Thus, QA can be a management tool to demonstrate regulatory compliance; a business efficiency tool to ensure consistent product quality and minimise risk; and also a communication tool to provide information to customers and consumers, wherever they are in the world (Baines and Ryan, 2002). Whilst quality is a negotiable product attribute between two parties, food safety is not. Food is either safe or unsafe. The FAO Assuring Food Safety and Quality: Guidelines for Strengthening National Food Control Systems publication (2003:3) states that: "Food safety refers to all those hazards, whether chronic or acute, that may make food injurious to the health of the consumer. It is not negotiable. Quality includes all other 
attributes that influence a product's value to the consumer." The FAO (2003) publication places particular importance on the fact that there is clear distinction between the terms food safety and food quality and this has implications for the development of organisational management systems that address one or the other or both (Manning and Soon, 2016).

The benefits of introducing a total quality management system in the hospitality sector have been widely identified both more generally (Saunders and Graham, 1992; Johns, 1993; Witt and Muhlemann, 1994; Camisón, 1996, Sureshchandar et al. 2001: Kapiki 2012) and with specific sectors such as hotels (Baldacchino, 1995; Wang et al. 2012; BenavidesVelasco et al. 2014). More recently the application of lean management principles has been considered as a means to drive efficiency in internal processes and reduce costs in the hospitality sector (Vlachos and Bogdanovic, 2013; Rauch et al. 2016). The focus of this paper is not on quality per se, but the development of quality management systems (QMS) and food safety management systems (FSMS) is often concurrent within the hospitality sector whether this is formalised, informal or at an intermediary stage between the two. Indeed in many larger organisations, management systems for food safety, quality and often environmental criteria too are merged into one integrated management system and the associated organisational culture is difficult to unpick to consider food safety culture in isolation.

\section{FSMS in the hospitality sector and attitudes of staff to food safety}

Food safety leadership is about setting a direction, aligning people to it and then motivating and inspiring them to achieve it (Griffith, 2014). Guchait et al. (2016) in their work considered one aspect of leadership namely leader behavioural integrity for food safety i.e. the extent to which leaders/supervisors consistently enacted or enforced food safety rules, protocols and concluded that those managers with high leader behavioural integrity influence food safety performance and reduce the risk of food borne illness. Luning et al. (2011a) determine four context factor characteristics that impact on the need for, and the depth of, food safety management activities in a given organisation as being:

\section{Internal}

- Product characteristics i.e. the intrinsic properties of initial materials and final menu items;

- Production characteristics i.e. the extrinsic conditions utilised during preparation, storage, cooking and service to customers;

- Organisational characteristics specific to the organisation itself. These can be subdivided into individual (people) characteristics, group characteristics (associated with food safety culture), organisational structures (division of tasks, responsibilities, rules, procedures, and information systems), which affect peoples' decision-making behaviour; and

\section{External}

- Chain characteristics i.e. the conditions during supply, and relationships with other companies and organisations in the supply chain (Luning and Marcelis, 2009; Luning et al. 2011a; Kirezieva et al. 2013).

Organisational culture (internal) and the wider operating environment (external) provide the overarching framework within which the FSMS operates. The FSMS comprises policies, procedures and protocols to ensure regulatory compliance, development of prerequisite programmes such as standard operating procedures, training programmes, auditing programmes and incorporates communication efforts, awareness of responsibilities, commitment by management, and consideration of the entire organisation as an integrated 
system that can affect food safety (Armstrong 1999; Powell et al. 2011). FSMS failure can occur through product, process or human failure or the emergence of a previously unknown food safety hazard (Manning, 2013). Therefore, food safety culture extends beyond the functional aspects of the FSMS. Thus human interaction with the products, processes and protocols within the FSMS is of critical importance to consider, map and where necessary improve behaviour, in order to maintain effective control of food safety risk.

FSMS in the hospitality sector within the European Union (EU) are mandated to be based on a hazard analysis critical control point (HACCP) approach. The importance in the hospitality industry of knowledge and understanding of the concept and application of HACCP (Taylor, 2001; Eves and Dervisi, 2005; Bolton et al. 2008; Taylor, 2008; Garayoa et al. 2011); food hygiene training (Seaman and Eves, 2006: Soares et al. 2012: Faour-Klingbeil et al. 2015); supervision (Griffith et al. 2010; Powell et al. 2011; Lee et al., 2012); lack of accountability (Lee et al. 2012); and appropriate resources, facilities and design (Clayton et al. 2002; Soares et al. 2012) to reduce food safety risk has been recognised. Assumptions that the provision of food hygiene knowledge alone will then lead to a change in worker attitudes and thus their performance is ill founded. The prevailing attitudes, normative standards and morale within an organisation form part of the organisational culture, which has an influence on the motivation of employees to transfer knowledge and training to actual behaviour within the workplace (Seaman and Eves, 2006). Taylor (2008) considered twenty-one barriers to HACCP and food safety in hospitality and they incorporate the knowledge-experience-attitudesbehaviour (K-E-A-B) aspects of food safety culture into their work. Baser et al. (2017) found a medium correlation between food safety knowledge and attitude in hotel staff, but a high correlation between food safety attitude and behaviour i.e. that knowledge alone without an attitudinal response will not necessarily lead to behavioural response. Food handler attitude mediates the relationship between knowledge and practice in restaurants and hotels (Ko, 2013; Baser et al. 2017; Zanin et al. 2017). Positive correlations were found between hygiene knowledge of restaurant business owners, their attitudes toward food hygiene and official food control, and the actual restaurant hygiene standard (Läikkö-Roto and Nevas, 2014). These studies have essentially assessed the relationship between knowledge, attitudes and practices (KAP) of food handlers with regard to food safety. Arendt et al. (2011) propose four factors that motivate employees to follow food safety practice: the resources available; the degree of communication between employees and supervisors; the rewards and sanctions employed within the organisation and the intrinsic motivators that influence behaviour.

Food handlers attitudes towards safe food handling in the hospitality sector have been researched by a number of studies including Clayton and Griffiths (2008) who highlight the impact of attitude (as previously described), subjective norm (the pressure perceived by food handlers as to whether or not they perform a behaviour as mediated by social group identity), descriptive norms, intention and perceived behavioural control (perceived availability of opportunities and resources necessary to perform the behaviour and/or the perceived ease or difficulty in exhibiting that behaviour), and a wish for legislative and procedural compliance (Coleman et al. 2000; Griffith, 2010; Faour-Klingbeil, 2015). One study suggests that perceived behavioural control was the most significant predictor (Mullan and Wong, 2009; FaourKlingbeil, 2015). Indeed Griffiths (2006) argues that in order to reduce the incidence of food borne-disease it is important to address food handler behaviour and its links with the FSMS and the food safety organisational culture. The aim of this paper is to undertake a thematic review of existing literature in order to consider how, in the hospitality sector, food safety management is framed and informed by the organisational food safety culture and the 
external conditions in which the business operates. Having set this context the paper then compares and contrasts existing food safety culture assessment tools with reference to their value in the hospitality sector.

\section{Food safety culture}

Culture applies meaning to the underlying values and beliefs held by the members of formal and informal social groupings (Buchann and Huczynski, 2004; Griffith et al. 2010) and also meaning to their shared assumptions i.e. attitudes and associated behaviours (Hellriegel and Slocum, 2004). Denison (1996) states that culture relates to the deep structure of organisations associated with values, beliefs and assumptions with meaning established via socialisation. Griffith (2014) describes organisational culture as an umbrella term under which multiple cultures may exist. This will be especially so where there is a tension between profitability and food safety and between the cost of implementing food safety and the benefit that is perceived by the organisation as a result. Food safety culture must take precedence over other cultures within the organisation including the drive for profitability (Griffiths et al. 2010) if customers are to be safeguarded. However, potential conflict in the prescribed aims and objectives of specific job roles or between senior management and other levels of management means that multiple cultures may not only exist, they may also flourish (Manning, 2018). It is important that the non-homogeneity and complexity of a given organisation's culture is recognised (Nyarugwe et al. 2016). Wright et al. (2012) define eight elements of food safety culture: leadership, ownership of safety, business priorities, risk perceptions, perception of food safety, competence, employee communication, procedures, and employee involvement in food safety.

De Boeck et al. (2015) did make a distinction between food safety climate and food safety culture stating that food safety culture is the overarching organisational framework associated with food safety arising from the interplay of actors within the organisation whereas food safety climate is the relative priority or the "meaning" given to food safety in an organisation or work unit as perceived individually or collectively by employees, i.e. it can be measured at individual or work unit or group level. Assessing food safety climate is therefore a means to capture the important aspects of the underlying food safety culture, in essence assessing the outermost level of food safety culture as defined by Griffiths (2014), but again this shows differentiation from how the terminology is used in the Griffiths model. Essentially De Boeck et al. (2015) argue food safety culture has two elements; one is the techno-managerial element distinguished by the FSMS and its operation (Luning and Marcelis, 2009) and the context in which it is operating in terms of the characteristics described earlier in this paper (Luning et al. 2011a). The second element of food safety culture is the human element described as food safety climate, the focus of the work described in De Boeck et al. (2015) i.e. that food safety climate is a sub-set of overall food safety culture. However the terms food safety climate and food safety culture are used interchangeably in the research (Jespersen et al. 2017) and a clear definition should be sought.

Organisational climate $(\mathrm{OC})$ has been described as a "set of characteristics that describe an organisation and that (a) distinguish the organisation from other organisations, (b) are relatively enduring over time, and (c) influence the behaviour of people in the organisation" (Forehand and Glimer, 1964; Lee et al. 2012). In contrast to Griffith (2014) stating that an organisation's "climate" was the outermost element of an organisation's culture, Denison (1996) concludes that the definitions of organisational culture and OC 
overlap and as such are not clearly differentiated showing there is no clear consensus on the definitions of OC and organisational culture. Manning et al. (2005) identified four dimensions of $O C$ in the tourism and hospitality industry, these being: (a) leadership facilitation and support; (b) professional and organisational spirit; (c) conflict and ambiguity; and (d) workgroup cooperation, friendliness, and warmth.

Powell et al. (2011) argue that food safety culture is built on a set of shared values followed by staff, with appropriate knowledge and full awareness of the associated risks, to consistently produce food in the safest way. Griffith's model of food safety culture (2014) applied to both food manufacturing and food service is based on the Schein model (1985) with three levels of culture:

- Level 1 - Food safety climate: outermost, visible layer of food business culture detected during audits and inspections and is observable. This level of culture is modified depending on internal and external constraints e.g. lack of resources, people, and presence of the auditor/inspector. This definition of the term climate is disputed in other sources, but is not explored further in this paper.

- Level 2 - Underpinning culture: the middle layer includes the organisation's espoused values (often unspoken) and guides the employees' behaviour and attitudes to authority and legislation. Depending on the depth of audit/inspection this level of culture can be determined.

- Level 3 - Core culture: the inner most layer that contains all the assumption by staff of what the organisation is all about. It includes core values that are invisible and often assumed.

Wright et al. (2012) characterised food safety cultures both in general food businesses and food service through their measureable behaviour i.e. through their willingness to comply:

- Proactive compliers - individuals who encourage compliance but may not go beyond good practice:

- Dependent compliers - individuals who wait upon advice or instruction to take action:

- Doubting compliers - individuals who doubt the significance of the risk of a breach of food safety standards; and

- Calculative non-compliers - individuals who intentionally breach standards for the sake of personal or organisational gain.

Griffith et al. (2010) determines the components of food safety culture as leadership, communication, staff commitment, resources, and risk awareness associated with food safety and hygiene. The Griffith et al. (2010) components were used as the structure for the food safety climate model developed by De Boeck et al. (2015). It is important to reflect on this ambiguity in use of terms when considering how food safety culture/climate assessment tools have been developed as the ambiguity can affect the validity of the conclusions drawn.

\section{Food safety culture/climate assessment tools}

Assessment tools are defined here both more generally and also with specific focus on tools used in the hospitality sector. Stakeholders such as governments, food safety authorities, sector organisations and consumer interest groups are interested in how effective an FSMS is and/or whether the cost of adopting an FSMS provides value in terms of improving food safety performance or reducing overall risk (Manning et al. 2006: Jacxsens et al. 2010; Luning et al. 2011b). Jespersen et al. (2017) identify five elements of food safety culture that can be assessed and evaluated using such tools: values and mission; people systems 
associated with knowledge, quality, effectiveness, communication, autonomy, expectations and risk; consistency which encompasses compliance, level and quality of formalisation with regard to food safety; enforceability versus trade-offs, technology enabled behaviours and access to an investment in infrastructure; adaptability i.e. the organisations approach to change, and problem solving; and finally risk awareness. The United Kingdom Food Standards Agency (FSA) commissioned work to develop a tool to diagnose culture in food business operators (Wright et al. 2012). The diagnostic tool was developed for use by local authority inspectors in identifying aspects of good/poorer safety cultures in food businesses, particularly aimed towards micro and small and medium sized (SMEs) businesses, and inspector viewpoints on this tool are described in paper seven of this themed journal edition. Thus FSMS and food safety culture diagnostic tools and toolkits are often questionnaire based with an associated binary or scale based scoring system at the core with some approaches also using staff interviews and/or staff surveys with associated advice or guidance to drive improvement (Wright et al. 2012).

Jespersen et al. (2016) also considered the aspects of the degree of the maturity of food safety culture using a five-stage maturity model based on the aspects mentioned in this paper previously of attitude, perceived behavioural control, social norm, past behaviour and behavioural intention. The five stages are Stage 1: doubt; Stage 2: React to; Stage 3 know of; Stage 4 Predict; and Stage 5: Internalise. This allows for a semi-quantitative approach to score by capability area at the level of production unit, and manufacturing site and allows for a ranking process. However it could be argued that the ability to rank and differentiate between organisations in terms of their scores in a meaningful way i.e. determining the actual food safety risk associated with a business that scores say $55 \%$; $60 \%$ or $65 \%$ is difficult, for example the difference in increased risk between an organisation that scores $70 \%$ and one that scores $65 \%$ and between $65 \%$ and $60 \%$ may not be the same level of magnitude for the same $5 \%$ difference. The tool described is of value though in showing the maturity over time of a single organisation, as are the other semi-quantitative tools described in this paper providing that both the validity and reliability of their repeated use can be demonstrated in one stand-alone business and also across a range of food business size and sectors. Jespersen et al. (2017) propose that results and associated inferences from any qualitative cultural evaluation methodology are impacted on by the validity (i.e. the accuracy of the data) and reliability (i.e. the consistency and repeatability) of the research.

Wright et al. (2012) identify aspects of food safety culture diagnostic tools that are used to assess the functioning of food safety culture and also additional mapping elements that can translate from assessment results to providing advice on how improvements can be made to food safety culture. Therefore Wright et al.'s tool is designed to frame the role of the inspector as an external agent to diagnose and then offer advice primarily to SMEs. With a view to determining maturity of food safety culture, and consideration that food safety culture tools could be developed to determine different aspects of food safety management and food safety culture, Luning et al. (2011a) distinguish between diagnostic tools that determine the level of performance of a FSMS; selection tools that are designed to help a selection process and determining the most appropriate analysis and detection system and improvement tools that are designed to drive improvement with the FSMS. Many food safety culture assessment tools are qualitative (Jespersen et al. 2017), or semi-quantitative (Luning et al. 2008; 2009; Jacxsens et al. 2009; Wright et al. 2012) i.e. elements of measurement can be represented with statements and associated numeric scales in order to give an output of a quantification of risk (Davidson et al. 2006). Qualitative assessment tools can assist 
assessors to detemine a certain level of risk and inform priority setting and allocation of resources (Coleman and Marks, 1999; Manning and Soon, 2013). Markowski and Mannan (2008) assert that binary, or scale based semi-quantitative risk assessment can be imprecise and vague and produce significant uncertainties concerning the actual risk category compared to approaches such as fuzzy logic. Aggregative food safety risk assessment tools based on fuzzy logic can be developed that enabled a structured risk assessment resulting in a single risk rating at a point in the food supply chain (Wang et al. 2011; Manning, 2013). Fuzzy logic is based on the assumption that in some logical approaches the answer is not binary, i.e. yes or no, but that depending on different variables and whether they are of influence or not there can be degrees of correct or incorrect values. However fuzzy logic assessment tools are difficult to implement at SME level without the use of software tools, which is why the focus on developing methods of value to industry has fallen up until now primarily on semiquantitative assessment tools.

A generic questionnaire survey is of limited value in highly heterogeneous work situations and alternative approaches need to be considered in order to develop valid and trustworthy safety culture measurement tools (Guldenmund, 2000; Jespersen and Wallace, 2017). Whilst some tools are based on self-assessment questionnaires or surveys (De Boeck et al. 2015; 2016), others use a multiple data source approach of self-assessment survey and observations (Wright et al. 2012) and self-assessment survey, observations and interviews and performance assessment (Jespersen et al. 2016). The Wright et al. (2012) diagnostic tool categories using qualitative descriptions that align to a business score for each food safety culture element defined. Boeck et al. (2015) developed a food safety climate scale based selfassessment survey with 27 indicators rather than an audit or inspection tool. Examples of FSMS diagnostic tools include FSMS diagnostic instrument (FSMS-DI) (Luning et al. 2008; 2009) and a microbiological assessment scheme (MAS) (Jacxsens et al. 2009). Boeck et al. (2016) combined the use of FSMS-DI; MAS and the food safety climate self-assessment tool described in De Boeck et al. (2015). Indicators should be developed that can show the degree to which food safety is prioritised, embedded, practiced, and requirements communicated to staff (Griffith, 2013). Indicators must be chosen that give a valid assessment of the prevailing food safety culture (Nyarugwee et al. 2016). Jacxsens et al. (2010) introduce the term food safety performance indicators (FSPI) which allow FSMS performance to be measured, validated and assessed. FSPI include microbiological criteria, number of product recalls, customer complaints. The indicators described here are associated with the FSMS specifically and its performance rather than the performance of those implementing the FSMS. The development of FSPI could be researched further with specific emphasis on the hospitality sector.

The Culture Excellence Survey is reviewed in many papers in this edition of the journal; it is an online food safety and quality survey that is currently used by thousands of small, medium and large businesses in hospitality, retail and manufacturing in 19 countries. It was created from a longitudinal mixed method research process (Taylor \& Rostron, 2018; Taylor \& Budworth) and measures 20 dimensions of culture across 4 categories: People (empowerment, reward, training, communication and teamwork), Process (systems, management control, co-ordination, consistency and premises), Purpose (vision, strategy, values, targets and metrics) and Proactivity (innovation and change, organisational learning, investment, external awareness and risk foresight). The British Retail Consortium (BRC) Global Standards have adopted a version of the Culture Excellence Survey in their Food Safety Culture Module using an assessment that has both a self-administered questionnaire and also 
a third-party assessment questionnaire. This voluntary module supports the information gathered during third party audits, alongside additional auditor observations of factors that impact on food safety culture (BRC, 2017). The resultant score allows for ranking of organisations to occur and provides strength to the third party audit process questioned by Griffith et al. (2017).

With particular emphasis on food service Griffith et al. (2017) considered mechanisms to assess both food safety management and food safety culture using semi-structured interviews rather than a self-assessment questionnaire and where possible the responses were verified using objective evidence such as documents, records and observations. This approach is considered by Griffith (2014) to be better than a traditional supply chain certification audit, which may only assess, as Griffith defines food safety climate, the visible outer layer of food safety culture. Griffith et al. (2017) also consider food safety culture as a developmental process addressing standards, communication, training and supervision, commitment and support, assessment and monitoring, consequences as a result of either good or bad behaviour and a continuous improvement approach (Plan-Do-Check-ActMonitor). Thus the Griffith et al. (2017) methodology has both a food safety management and food safety culture assessment stage and also elements of culture maturity assessment.

Cost versus benefit is an important consideration when implementing a food safety culture assessment approach (Kane, 2011) and this special edition focuses in more detail in how value and satisfaction in use is determined (see Taylor and Rostron, 2018; Emond, 2018), and how survey data can be used as a mechanism for implementing and measuring the impact of successful change initiatives (see Caccamo et al., 2018; Nouaimeh et al. 2018), demonstrating an organisation's ability to generate and capture value when focusing on measuring and improving organisational culture.

\section{Conclusion}

FSMS provide a framework for determining the resources required and the procedures and protocols, monitoring and verification necessary to deliver safe food. However, a performance gap has been identified in the literature between intended and actual practice and the factors, rituals and behaviours that mediate this gap have been termed by many as "food safety culture". The multiple definitions of food safety culture do not help to create uniformity in approach in the hospitality sector to either assessment of the existence of a food safety culture or the degree of its maturity, nor an ability to benchmark across tools. The differentiation in scoring and weighting also needs to develop further as there is a cost implication for investing in food safety culture and the cost: benefit analysis of investment versus reward is not clearly contextualised. However much work has been undertaken to quantify benefit associated with quality costs and much of this could be translated to this topic.

Multiple food safety culture tools have been considered in this review and one in particular gains specific focus in this special edition. Whilst the literature demonstrates that having food safety knowledge does not necessarily lead to behaviour that promotes food safety, the knowledge-experience-attitude-behaviour (KEAB) dynamic of food safety culture is of crucial importance. The challenge that is presented with this paper is that food service organisations, often as a result of high staff turnover, are not homologous in terms of the KEAB dynamic, and there is a differential in personal and collective cultural backgrounds and as a result food safety practice. These factors are worthy of further empirical study in the hospitality industry. 


\section{References}

Arendt, S.W., Ellis, J.D., Strohbehn, C., Paez, P., (2011). “Development and use of an instrument to measure retail foodservice employees' motivation for following food safety practices". Journal of Foodservice Business Research Vol. 14, No. 1, pp. 68-85.

Armstrong, G. (1999). "Towards an integrated hygiene and food safety management systems: the Hygieneomic approach". International Journal of Food Microbiology, Vol. 50, pp. 19-24.

Baldacchino, G., (1995). "Total quality management in a luxury hotel: a critique of practice". International Journal of hospitality management, Vol 14, No. 1, pp.67-78.

Baines, R.N. and Ryan, P. (2002), "Global trends in quality assurance", paper presented at the Trade Partners UK and Ministry of Agriculture "Modern Food Chain" Seminar, Kuala Lumpur.

Baser, F., Ture, H., Abubakirova, A., Sanlier, N. and Cil, B., (2017). "Structural modeling of the relationship among food safety knowledge, attitude and behavior of hotel staff in Turkey". Food Control, Vol. 73, pp.438-444.

Benavides-Velasco, C.A., Quintana-García, C. and Marchante-Lara, M., (2014). "Total quality management, corporate social responsibility and performance in the hotel industry". International Journal of Hospitality Management, Vol. 41, pp.77-87 Bolton, D.J., Meally, A., Blair, I.S., McDowell, D.A. and Cowan, C., (2008). "Food safety knowledge of head chefs and catering managers in Ireland". Food Control, Vol. 19, No. 3 , pp.291-300.

BS EN ISO 9000 (2015) Quality management systems. Functions and vocabulary. BSI London. Buchann, D. and Huczynski, A. (2004), Organizational Behaviour: An Introductory Text, 5th Ed., Pearson Education Limited, Madrid.

Camisón, C., (1996). "Total quality management in hospitality: an application of the EFQM mode"l. Tourism management, Vol. 17, No. 3, pp.191-201.

Clayton, D.A., Griffith, C.J., Price, P. and Peters, A.C., (2002). "Food handlers' beliefs and selfreported practices". International journal of environmental health research, Vol. 12, No. 1, pp.25-39.

Clayton, D.A. and Griffith, C.J., (2008). "Efficacy of an extended theory of planned behaviour model for predicting caterers' hand hygiene practices". International Journal of Environmental Health Research, No. 18, No. 2, pp.83-98.

Coleman, P., Griffith, C. and Botterill, D., (2000). "Welsh caterers: an exploratory study of attitudes towards safe food handling in the hospitality industry". International Journal of Hospitality Management, Vol. 19, No.2, pp.145-157.

Coleman, M.E. and Marks, H.M. (1999), "Qualitative and quantitative risk assessment", Food Control, Vol. 10, pp. 289-97.

Davidson, V.J., Ryks, J. and Fazil, A. (2006), "Fuzzy risk assessment tool for microbial hazards in food systems", Fuzzy Sets and Systems, Vol. 157, pp. 1201-10.

De Boeck, E., Jacxsens, L., Bollaerts, M., Uyttendaele, M. and Vlerick, P., (2016). “Interplay between food safety climate, food safety management system and microbiological hygiene in farm butcheries and affiliated butcher shops". Food Control, Vol. 65, pp.78-91.

De Boeck, E., Jacxsens, L., Bollaerts, M., and Vlerick, P., (2015). "Food safety climate in food processing organisations. Development and validation of a self-assessment tool". Trends in Food Science and Technology, Vol. 46, pp.242-251. 
Denison, D.R. (1996), "What is the difference between organisational culture and organisational climate? A Native's Point of View on a Decade of Paradigm Wars", The Academy of Management Review Vol. 21, No. 3, pp. 619-654

Early, R. (1995), A Guide to Quality Management Systems for the Food Industry, Blackie Academic and Professional, London.

Emond, B. (2018) "The importance of measuring food safety and quality culture: results from a global training survey", Worldwide Hospitality and Tourism Themes, Vol 10, No. 2.

Eves, A. and Dervisi, P., (2005). "Experiences of the implementation and operation of hazard analysis critical control points in the food service sector". International Journal of Hospitality Management, Vol. 24, No. 1, pp.3-19.

FAO. (2003). Assuring food safety and quality: Guidelines for strengthening national control systems. FAO Food and Nutrition Paper 76. ISBN 0254-4725.

Faour-Klingbeil, D., Kuri, V. and Todd, E., (2015). "Investigating a link of two different types of food business management to the food safety knowledge, attitudes and practices of food handlers in Beirut, Lebanon". Food Control, Vol. 55, pp.166-175.

Forehand, G.A. and Von Haller, G., (1964). Environmental variation in studies of organizational behavior. Psychological bulletin, Vol. 62, No. 6, p.361.

Garayoa, R., Vitas, A.I., Díez-Leturia, M. and García-Jalón, I., (2011). “Food safety and the contract catering companies: Food handlers, facilities and HACCP evaluation". Food Control, Vol. 22, No. 12, pp.2006-2012.

Griffith, C.J., Griffith, C.J., Jackson, L.M., Jackson, L.M., Lues, R. and Lues, R., (2017). "The food safety culture in a large South African food service complex: Perspectives on a case study". British Food Journal, Vol. 119, No. 4, pp.729-743.

Griffith, C. (2014). Developing and Maintaining a Positive Food Safety Culture. 1st Edition. Highfield Publications.

Griffith, C. (2013). "Advances in understanding the impact of personal hygiene and human behaviour on food safety". Advances in Microbial Food Safety Vol. 1, pp. 401-416.

Griffith, C. J., Livesey, K. M., and Clayton, D. (2010). "The assessment of food safety culture." British Food Journal, Vol. 112, pp. 439-456.

Griffith, C.J., (2010). "Do businesses get the food poisoning they deserve? The importance of food safety culture". British Food Journal, Vol. 112, No. 4, pp.416-425.

Griffith, C.J., (2006). "Food safety: where from and where to?" British Food Journal, Vol. 108, No. 1, pp.6-15.

Guchait, P., Neal, J.A. and Simons, T., (2016). "Reducing food safety errors in the United States: Leader behavioral integrity for food safety, error reporting, and error management." International Journal of Hospitality Management, Vol. 59, pp.11-18.

Guldenmund, F.W. (2000). "The nature of safety culture: A review of theory and research." Safety Science, Vol. 34, No. (1-3), pp. 215-257.

Hellriegel, D., and Slocum, J. W. (2004). Organizational behavior. Beauceville, Quebec:SouthWestern.

Jacxsens, L., Uyttendaele, M., Devlieghere, F., Rovira, J., Gomez, S.O. and Luning, P.A., (2010). "Food safety performance indicators to benchmark food safety output of food safety management systems". International Journal of Food Microbiology, Vol. 141, pp.S180-S187. Jacxsens, L., Kussaga, J., Luning, P.A., Van der Spiegel, M., Devlieghere, F., Uyttendaele, M., (2009). "A microbial assessment scheme to support microbial performance measurements of food safety management systems". International Journal of Food Microbiology Vol. 134, pp. 113-125. 
Jespersen, L., Griffiths, M., and Wallace, C.A., (2017). "Comparative analysis of existing food safety culture evaluation systems." Food Control, Vol. 79, pp.371-379.

Jespersen, L. and Wallace, C.A., (2017). "Triangulation and the importance of establishing valid methods for food safety culture evaluation". Food Research International, Vol. 100, pp.244-253.

Jespersen, L., Griffiths, M., Maclaurin, T., Chapman, B. and Wallace, C.A., (2016).

"Measurement of food safety culture using survey and maturity profiling tools". Food

Control, Vol. 66, pp.174-182.

Johns, N., (1993). "Quality management in the hospitality industry: Part 3. Recent developments". International Journal of Contemporary Hospitality Management, Vol. 5, No. $1 \mathrm{pp}$.

Kane, K. (2011), "Evolving methods of HACCP: costs and benefits", Worldwide Hospitality and Tourism Themes, Vol. 3 No. 5, pp. 413-21.

Kapiki, S.T., (2012). "Quality management in tourism and hospitality: An exploratory study among tourism stakeholders". International Journal of Economic Practices and Theories, Vol. 2, No. 2, pages 9

Kirezieva, K., Nanyunja, J., Jacxsens, L., van der Vorst, J.G., Uyttendaele, M. and Luning, P.A., (2013). "Context factors affecting design and operation of food safety management systems in the fresh produce chain". Trends in food science \& technology, Vol. 32, No. 2, 108-127. Ko, W.H., (2013). "The relationship among food safety knowledge, attitudes and selfreported HACCP practices in restaurant employees". Food control, Vol 29. No. 1, pp.192197.

Läikkö-Roto, T. and Nevas, M., (2014). "Restaurant business operators' knowledge of food hygiene and their attitudes toward official food control affect the hygiene in their restaurants". Food Control, Vol. 43, pp.65-73.

Lee, J.E., Almanza, B.A., Jang, S., Nelson, D.C and Ghiselli, R.F. (2012). "Does

transformational leadership style influence employees' attitudes toward food safety practices?" International Journal of Hospitality Management, Vol. 33, pp. 282-293 Luning, P. A., Jacxsens, L., Rovira, J., Oses, S. M., Uyttendaele, M., and Marcelis, W. J. (2011a). "A concurrent diagnosis of microbiological food safety output and food safety management system performance: cases from meat processing industries". Food Control, Vol. 22, pp. 555-565.

Luning, P.A., Marcelis, W.J., Rovira, J., Van Boekel, M.A.J.S., Uyttendaele, M. and Jacxsens, L., (2011b). "A tool to diagnose context riskiness in view of food safety activities and microbiological safety output". Trends in food Science \& technology, Vol. 22, pp.S67-S79. Luning, P.A., and Marcelis, W.J. (2009). Food Quality Management: technological and managerial principles and practices. Wageningen Academic Publishers, Wageningen. The Netherlands. ISBN 987-90-8686-116-3.

Luning, P.A., Marcelis, W.J., Rovira, J., Van der Spiegel, M., Uyttendaele, M., Jacxsens, L., (2009). "Systematic assessment of core assurance activities in company specific food safety management systems". Trends in Food Science \& Technology Vol. 20, pp. 300-312. Luning, P.A., Bango, L., Kussaga, J., Rovira, J. and Marcelis, W.J., (2008). “Comprehensive analysis and differentiated assessment of food safety control systems: a diagnostic instrument". Trends in Food Science \& Technology, Vol. 19, No. 10, pp.522-534.

Manning, L. (2017). "The interaction between organizational sub-cultures and its influence on food safety management", Journal of Marketing Channels, Vol. 24, No. 3-4, pp. 1-10 
Manning, L., and Soon, J.M., (2016). "Food safety, food fraud and food defense: a fast evolving literature", Journal of Food Science, Vol. 81, No. 4, R823-R834

Manning, L., and Soon, J.M., (2013), "Mechanisms for assessing food safety risk", British Food Journal, Vol. 115, No. 3 pp. 460-484

Manning, L., (2013), "Development of a food safety verification risk model", British Food Journal, Vol. 115, No. 4, pp. 575-589

Manning, L., Baines, R. N., and Chadd, S. A. (2006). "Food safety management in broiler meat production". British Food Journal, Vol. 108, No. 8, pp. 605-621.

Manning, M.L., Davidson, M., Manning, R.L., (2005). "Measuring tourism and hospitality employee workplace perceptions". International Journal of Hospitality Management Vol. 24, No. 1, pp. 75-90.

Markowski, A.S. and Mannan, M.S. (2008), "Fuzzy risk matrix", Journal of Hazardous Materials, Vol. 159, pp. 152-7.

Mullan, B. A., and Wong, C. L. (2009). "Hygienic food handling behaviours. An application of the theory of planned behaviour". Appetite, Vol. 52, No. 3, pp. 757--761.

Nayak, R. (2018) "Food safety culture - the food inspectors' perspective", Worldwide Hospitality and Tourism Themes, Vol 10, No. 2.

Nouaimeh, N., Pazhanthotta, R., Bulatovic-Schumer, R. and Taylor, J.Z. (2018) "Measuring and improving food safety culture in a large catering company: A case study", Worldwide Hospitality and Tourism Themes, Vol 10, No. 2.

Nyarugwe, S.P., Linnemann, A., Hofstede, G.J., Fogliano, V. and Luning, P.A., (2016). "Determinants for conducting food safety culture research". Trends in Food Science \& Technology, Vol. 56, pp.77-87.

Oakland, J.S. (1993), Total Quality Management: The Route to Improving Performance, Butterworth-Heinemann, Oxford.

Powell, D.A., Jacob, C.J., Chapman, B.J., (2011). “Enhancing food safety culture to reduce rates of foodborne illness". Food Control Vol. 22, No. 6, pp. 817-822.

Rauch, E., Damian, A., Holzner, P. and Matt, D.T., (2016). "Lean Hospitality-Application of Lean Management methods in the hotel sector". Procedia CIRP, No. 41, pp.614-619.

Saunders, I.W. and Graham, M.A., (1992). "Total quality management in the hospitality industry". Total Quality Management, Vol. 3, No. 3, pp.243-256

Seaman, P. and Eves, A., (2006). The management of food safety-the role of food hygiene training in the UK service sector. International Journal of Hospitality Management, Vol. 25, No. 2, pp.278-296

Soares, L.S., Almeida, R.C., Cerqueira, E.S., Carvalho, J.S. and Nunes, I.L., (2012).

"Knowledge, attitudes and practices in food safety and the presence of coagulase-positive staphylococci on hands of food handlers in the schools of Camaçari, Brazil". Food Control, Vol. 27, No. 1, pp.206-213.

Schein, E. H. (1985). Organizational culture and leadership. San Francisco, CA: Jossey-Bass. Sureshchandar, G.S., Rajendran, C. and Anantharaman, R.N., (2001). "A conceptual model for total quality management in service organizations". Total quality management, Vol. 12, No. 3, pp.343-363.

Taylor, J. Z. and Budworth, L. (2018) "Food safety culture: patterns and trends from a quantitative analysis of the Culture Excellence assessment program", Worldwide Hospitality and Tourism Themes, Vol 10, No. 2. 
Taylor, J.Z. and Rostron, K. (2018) "The development of a safety and quality culture assessment tool from a longitudinal, mixed method research journey", Worldwide Hospitality and Tourism Themes, Vol 10, No. 2.

Taylor, J.Z, (2008). "HACCP for the hospitality industry: a psychological model for success". International Journal of Contemporary Hospitality Management, Vol. 20, No. 5, pp.508-523 Taylor, E. (2001). "HACCP in small companies: benefit or burden?" Food Control, Vol. 12, No. 1, pp. 217-222.

Vlachos, I. and Bogdanovic, A., (2013). "Lean thinking in the European hotel industry". Tourism Management, Vol. 36, pp.354-363.

Wang, C.H., Chen, K.Y. and Chen, S.C., (2012). "Total quality management, market orientation and hotel performance: The moderating effects of external environmental factors." International Journal of Hospitality Management, Vol. 31, No. 1, pp.119-129. Wang, X., Li, D. and Shi, X. (2011), "A fuzzy enabled model for aggregative food safety risk assessment in food supply chains", Production Planning and Control, iFirst, available at: www.tandfonline.com/doi/abs/10.1080/09537287.2011.561812\#preview (accessed 21 June 2011).

Witt, C.A. and Muhlemann, A.P., (1994). "The implementation of total quality management in tourism: some guidelines". Tourism management, Vol. 15, No. 6, pp.416-424.

Wright, M., Leach, P., and Palmer, P. (2012), A Tool to Diagnose Culture in Food Business Operators Food Standards Agency.

Zanin, L.M., da Cunha, D.T., de Rosso, V.V., Capriles, V.D. and Stedefeldt, E., (2017).

"Knowledge, attitudes and practices of food handlers in food safety: An integrative review." Food Research International, Vol. 100, pp.53-62. 